and presented strong evidence dorived in part from the results of more than 100 field trials conducted from the Rothamsted Experimental Station that the effects on crop yield of organic manures based on straw are for the most part produced by the plant nutrients which the manures contain. On soils which tend to compact, strawy manures, but not sewage sludge, increase the yield of crops to a greater extent than can be explained by their content of plant nutrients. This appears, as work at the National Vegetable Research Station, Wellesbourne, and Rothamsted Experimental Station has shown, to be the consequence of a change in the geometry of the soil which prevents it from compacting and increases the volume of larger pores, and consequently the amount of water which can be held at low tension. In ley fertility experiments, the effects of leys on subsequent crops have proved to be largely due to increases in the supply of plant foods rather than to increases in the proportion of water-stable crumbs. Organic matter per se does not appear to have any special properties influencing crop yield except on special soils where the effects are shown only by particular types of organic matter. It is now important to concentrate experimental work on these special soils (which are thought to occupy about one-tenth of the arable land of England), using factorial experiments so designed that the effects of nutrients can be measured separately.

The final paper was one by Dr. R. Waite (Hannah Dairy Research Institute, Ayr) on "The Chemical Composition of Grasses in Relation to Agronomical Practice". He emphasized that modern tochniques of grassland management have resulted in greatly increased yields of digestible nutrients and presented data from his own experiments carried out at the Hannah Dairy Research Institute on the changes in composition of leafy herbage from several species of grasses during the growing season. The most significant change was in the fructosan : protein ratio, which was high in the early part of the season and low in the autumn. The former type of herbage would be expected to promote a predominantly propionic acid type of rumen fermentation, which would stimulate the production of non-fatty solids in the milk of cows and promote fattening in beef animals. Herbage low in soluble carbohydrates, on the other hand, would encourage an acetic acid type of fermentation in the rumen and the resulting mixture of volatile fatty acids would be used more efficiently for butter-fat than for solidsnot-fat production or for fattening. Herein may well lie the superiority commonly attributed to spring compared with autumn grass for fattening and milking animals.

The symposium ended with a summing-up by Prof. P. W. Arnold (University of Newcastle upon Tyne), who high-lighted the major themes from the various papers and directed attention to some of the important gaps in our knowledge of the way in which plants interact with their environment.

The majority of papers read at this meeting were mainly concerned with the quantitative aspect of the production of plant foods and, indeed, this aspect covers a vast range of problems. The qualitative aspect of the influence of the environment on plants for human and animal consumption is of at least equal interest to nutritionists and might well provide the subject for another symposium.

The re-statement at this meeting of the fundamental dependence of the animal kingdom on the plant was most salutary, and a reminder of the rate at which the total food requirements of the human population of the globe are increasing cen never be given too often. It is clear, however, that basic information on the methods by which the production of plant foods can be increased by the use of fortilizers, by growing improved varieties of crops, by irrigation and by better husbandry is freely available. The application of this knowledge is largely a problem of administration, education, finance, power supply, engineering and industrial production, and the avoidance of famine in the latter quarter of this century depends on its solution. The outlook is not wholly depressing, for it has been estimated that by the adoption of improved agricultural techniques, including the more efficient use of water, it would be possible to double the present yield from each acre of land at present under cultivation.
T. G. TAYLOR

\title{
SEARCHING FOR CREATIVITY
}

$\mathrm{T}$ HE search for creativity - in all its forms - would seem to be commendable and, indeed, of suprome impor. tance for the future of man, yet, reviewing progress so far achieved, P. E. Vernon can rate it no higher than the "latest fashion in American educational psychology"1. Those who have interested themselves in the problem have been moved by the impression that the whole educational system fosters conformist attitudes among pupils and students, which gain further support from present-day intelligence and aptitude tests. Prof. Vernon doubts if these strictures necessarily apply to the selective tests of pupils in England and Wales at $11+$ and $18+$.

He refers to the work of Calvin Taylor, who, on the basis of a number of investigations, including some carried out on industrial and Air Force scientists, maintains that in adult life there is little association between productivity and originality, and previous educational achievement; in fact, the correlations between the results of tests for creativity on one hand, and intelligence on the other, are not greater than $0 \cdot 2-0 \cdot 4$.

In this context, Prof. Vernon thinks that L. M. Terman's long-term follow-up of a group of children of high intelligence quotient merits attention, both because the test used-Stanford-Binet-was a good one, and because the scores obtained in tests in early youth have been compared with later achievement over the best part of a life-time. As a whole, the group has been very productive in the arts and sciences, although scarcely any member could be characterized as a genius. Here, intelligence is of some relevance, as it is in the findings of Terman and C. M. Cox that, from their biographies, few men in history of outstanding ability had an intelligence quotient below 120; while D. W. Mackinnon's results suggest that above a certain minimum figure, about 120, intelligence quotient plays a relatively minor part in creativity.

J. P. Guilford has carried out a long series of investigations of high-grade adults, and claims to have identified about 60 separate factors concerned with mental ability. Prof. Vernon questions the validity of these factors, partly because they have not received full confirmation from other workers but chiefly because he considers that in. itself factorial analysis of mental quality cannot produce the answers unless the factors correspond with what is recognized as 'originality' in daily life.

Another series of tests, similar to Guilford's, has been applied by J. W. Getzels and P. W. Jackson, this time on young high-school pupils. In their case, one group in the top 20 per cent on creativity tests, but not of outstanding intelligence quotient, were compared with another group from the top 20 per cent for intelligence but not of outstanding originality. In scholastic achievement both groups did about equally well; but since, as Vernon points out, the intelligence quotient of the group of high creativity 
averaged 127, as against 150 for those of higher intelligence quotient, the finding is of limited significance.

In this survey, however, on personality traits and sociometric status, the group of superior intelligence quotient were rated by their teachers higher than the more ereative, which leads Vernon to suggest that, in England and Wales, some of the more 'original' 18-yearolds may fail to find places at universities because they were unpopular with their head teachers, and not good mixers.

As C. Burt has pointed out, in the researches by Getzels and Jackson, correlations between separate tests for creativity were about on the same level as they were with intelligence tests, so that in these studies Vernon can find no evidence for a factor for creativity distinct from $g$ and $v$. He doubts whether those for creativity cover more ground than the typical battery of tests for verbal intelligence, English and arithmetic already in presentday use. His main eriticism, however, is that the tests which Getzel, Guilford and others have devised give no support to the assumption that they are valid for creativity in general: follow-up data are not available, and the gap between tests at about the time of entry to the secondary school and true creativity at the university is much too great.

As indications of originality, Prof. Vernon holds that tests like these scarcely go beyond empirical impressions which indicate that, in general, creative people tend to be rather solitary, independent, non-conformist, with strong drives and motivations on distant goals (Taylor); lone wolves with an overriding sense of the worth of their own ideas (Anne Roe); far more given to intuition than sensation type thinking, with a strong streak of femininity, often having suffered from unhappy childhoods and being rebellious at school and university (Mackinnon); and displaying humour and wit, while being unconventional in their attitudes and aspirations (Getzels and Jackson). Besides, such criteria fail to distinguish really creative people from rebels, delinquents, beatniks, introverts, idealists, etc. Prof. Vernon's opinion is that leisure time interests between 12 and 16 , like scientific hobbies and research, poetry and artistic activities, may have some predictive value; but, altogether, efforts may be misdirected if they set out to assess creativity in general, for it may turn out to be strongly individual and specific.

In final conclusion, Prof. Vornon disclaims any desire to disparage research into the assessment of creativity, but in his mind the crucial problem is to devise tests which do not require a long follow-up. He feels that present appraisals by schools and universities are heavily biased in favour of conventional attainment, but research into home, leisure and educational backgrounds might be rewarding, and the influence of an inspiring teacher might be tremendously important.

R. Weatherall

\section{RECORDINGS FROM SATELLITE Alouette I}

\section{A Very-low-frequency Plasma Resonance}

$\mathrm{A}^{\mathrm{N}}$ unusual band of noise observed in the Alouette I 1 satellite has been reported by Barrington and Belrose ${ }^{1}$, who noted that the band had a sharp lower frequency cut-off which usually increased in frequency with decreasing latitude of the satellite. Since this lower cut-off frequency varies consistently with the location of the satellite, it is deduced that the observed changes in this frequency arise from spatial rather than temporal effects. Because the lower cut-off frequency is sharp and changes measurably within a few seconds, we may deduce that the horizontal field of view of the satellite for this band is at most a few tens of kilometres.

From observations of triggering of this band by both atmospherics and whistlers, Brice et al. ${ }^{2}$ concluded that the noise was generated at the same height as the satellite. Thus the observed noise band is generated in the immediate vicinity of the satellite. Other evidence has been obtained suggesting that triggering of this band is enhanced for triggering signals propagating with large angles between the wave normal and the Earth's magnetic field. Furthermore, from examination of simultaneous verylow-frequency recordings made by the satellite and by ground-based stations, it is found that the Alouette hiss band is never observed on ground-based recordings.

The observation of spikes in the Alouette top-side sounder at the resonance frequencies for the ambient plasma ${ }^{3}$ suggests the Alouette hiss hand arises from a similar plasma resonance at very low frequencies. The only resonance for the frequencies of interest $(5-10 \mathrm{kc} / \mathrm{s})$ at the satellite height is the lower hybrid resonance ${ }^{4}$ which defines a cut-off frequency for propagation transverse to the Earth's magnetic field. Other features of this resonance support the hypothesis that the lower cut-off frequency of the Alowette hiss band is the lower hybrid resonance for the ambient plasma.

In a subsequent paper, it will be shown that from a knowledge of the electron plasma and gyrofrequencies and the lower hybrid resonance frequency, an effective mass for the ions in the ambient plasma may be determined.
Thus this hiss band may provide a powerful diagnostic tool for determining the ionic constituents of the plasma surrounding a satellite.

Assuming that the suggestion made above is correct, the observation of the Alouette hiss band provides, to the best of our knowledge, the first experimental confirmation of the existence of the lower hybrid resonance.

We thank Mr. John Katsufrakis of Stanford for pointing out a number of the unusual features of the Alowette hiss hand.

\section{N. M. Brice *}

R. L. SмIтH

Radioscience Laboratory, Stanford, California.

* Present address: Faculty of Engineering, Carleton University, Ottawa, Canada.

${ }^{1}$ Barrington, R. E., and Belrose, J. S., Nature, 198, 651 (1963).

${ }^{2}$ Brice, N. M., Smith, R. L., Belrose, J. S., and Barrington, R. E. (following communication)

${ }^{3}$ Calvert, W., and Goe, G. B., J. Geophys. Res., 68 (22), 6113 (1963).

${ }^{4}$ Stix, T. H., The Theory of Plasma Waves (McGraw-Hill Book Co., New York, 1962).

\section{Triggered Very-low-frequency Emissions}

Barrington and Belrose ${ }^{1}$ have reported that on occasion the very-low-frequency recordings from Alouette $I$ satellite (altitude, $1,000 \mathrm{~km}$ ) showed bursts of noise triggered by atmospherics which had propagated upwards to the satellite (that is, short fractional-hop whistlers) suggesting that very-low-frequency emissions were triggered at heights of less than $1,000 \mathrm{~km}$.

Since some hypotheses for the generation of very-lowfrequency emissions suggested generation in or near the ionospheric $F$-region ${ }^{2,3}$, while for other hypotheses generation is more likely near the top of a magnetic field line path ${ }^{4-6}$, it might be suggested that triggered emissions observed in Alovette could help to identify the mechanism responsible for generation of very-low-frequency emissions observed on ground-based recordings. However, further 